\title{
Die kanonbegrip as Bybels-teologiese probleem
}

PM Venter

\section{Abstract \\ The canon concept as problem in Biblical theology}

Reading the Bible in the context of its canonicity has become the general trend in the Theology of the Old Testament. This article shows what such contextual reading implies. The conclusion is drawn that it will eventually also bring about a new kind of canon history.

\section{WOORD VOORAF}

Hierdie artikel word opgedra aan prof JP Oberholzer, my eertydse promotor en huidige departementshoof. Hiermee betoon ek my waardering vir 'n persoon wat die unieke vermoë besit om deurtastende kritiek met opregte deernis vir die mens agter die woorde, te kombineer.

\section{DIE KANON AS KONTEKS VIR OU-TESTAMENTIESE TEOLOGIE}

In 'n tendensstudie nä die gang van die Ou-Testamentiese teologie in die sewentigerjare, het prof Oberholzer onder andere as riglyn vasgelê dat daar 'n 'behoefte (is) aan 'n Bybelse Teologie wat die kanon as konteks het' (Oberholzer 1976: 160). Hierin het hy hom aangesluit by die werk van J Bright, $\mathrm{H}$-J Krauss en veral BS Childs. Dit was veral Childs wat die standpunt verdedig het dat die teologiese betekenis van die Ou Testament vir die Ou-Testamentiese teologie uit te wys nie. Hy teks van die gegewe kanon gelees en bestudeer word. Childs was natuurlik nie die eerste persoon om die belang van die kanonisiteit van die Ou-Testament eers duidelik sal word wanneer dit binne die konhet hom hierin aangesluit by 'n gedagte wat GE Wright in die sestigerjare reeds begin ontwikkel het. In sy reaksie op die histories-kritiese navorsing na die tradisie waaruit die Ou Testament ontstaan het, het 
Childs veral klem gelê op die teologiese implikasie van daardie navorsing. Daardeur het hy 'n eie weg ingeslaan wat die kanonvraagstuk in die sentrum van Ou-Testamentiese teologie geplaas het vir die dekade daarna en bes moontlik tot aan die einde van die tweede millennium na Christus. (Terrien 1984: 132).

\section{GE WRIGHT EN DIE KANONVRAAGSTUK}

Wright het in 1969, in die laaste hoofstuk van sy boek oor die verband tussen $\mathrm{Ou}$ Testament en teologie, aandag gegee aan die teologiese vraagstuk van die kanon. Hy het geworstel met vraagstukke soos die bestaan van ' $n$ afgeslote kanon en die wyse waarop die Ou Testament as geslote kanon teologies hanteer moet word. In sy soektog na antwoorde wend Wright hom tot die gebied van die totstandkoming en finalisering van die Bybelse kanon. Wright betrek dus die kanongeskiedenis in die navorsing na die Bybelse teologie. Die Bybel is die eindresultaat van ' $n$ lang proses van tradisievorming. Dit was ' $n$ baie dinamiese proses, ' $n$ tradisie wat voortdurend besig was om te ontwikkel ('a developing tradition': Wright 1969: 169). Soos uit die eindproduk blyk, was die tradisie self 'n proses waarin 'n geweldige groot verskeidenheid van materiaal en gesigshoeke hanteer is. Ouer oorlewering is telkens herwaardeer volgens die waarde wat dit vir die kontemporêre geslag gehad het. Op 'n stadium is hierdie proses van herevaluering plotseling gestaak 'and determined to be canonically complete' (Wright 1969: 176). Hierdie skielike beëindiging kom eienaardig voor, dit 'seems to have been almost an artificial cutting off of something alive, evolving, moving, like an organism' (Wright 1969: 169). Dit kom voor asof die beëindiging telkens ' $n$ ad hoc beslissing van die gemeenskap was. Om redelik onbekende redes het hulle besluit waar hulle die proses wou staak en watter stadium van die ontwikkeling van die tradisie hulle wil kanoniseer. Sedert die tyd van Esra, toe Wet en verbondvernuwing aan mekaar verbind is tot in die hede, is dit vir Wright opvallend dat die hantering van kanonieke materiaal steeds aan die hand van 'n 'authoritative core' (Wright 1969: 180) geskied het. Vanuit hierdie gesaghebbende kern, wat as 'interpretative principle' (Wright 1969: 180) gefunksioneer het, is die res van die oorgelewerde materiaal verstaan en bymekaar gehou. Die beginsel van 'n kanon-indie-kanon, 'n norma normans-tipe teologie van' $n$ bepaalde gemeenskap in ' $n$ bepaalde tyd, is dus histories die vertrekpunt van waaruit die geheel van die Bybelse materiaal gelees en teologies verstaan is. Die 
aangewese weg vir die huidige Ou-Testamentiese teologie sou dus ook wees om eweneens vanuit een sentrale begrip die geheel van die $\mathrm{Ou}$ Testament te lees.

\section{CHILDS EN DIE KANONKONTEKS}

Die gedagtegang van Wright sluit gedeeltelik aan by die diakroniese tradisie-historiese benadering, wat sedert Von Rad baie sterk op die voorgrond getree het. Dit wyk egter daarvan af deurdat Wright die klem laat val op die afeindigingsfases van hierdie proses, die moontlike motiewe daarvan en veral die teologiese betekenis daarvan. By navolgers van die tradisie-historiese benadering, soos H Gese, DA Knight, RB Laurin en SE McEvenue, bestaan daar 'geen kwalitatiewe verskil tussen tradisie en kanon, tussen die gesag van die tradisie in die voorkanon tradisiebou proses en die finale kanonomvorming van die teks tot Skrif nie' (Hasel 1985: 41).

BS Childs sluit by die gedagtegang van Wright aan deur ook onderskeid te tref tussen die tradisiefases en die eindfase waarin die kanonvorm tot stand kom. Hy is van mening dat die finale kanonvorm van die Bybelteks die enigste fase is wat teologies normatief is en dat geen voorafgaande stadium van die tradisieproses enigsins van gelyke waarde is vir die Bybelse teologie nie.

Childs tref onderskeid tussen 'die historiese vraagstuk van die ontwikkeling van die kanon' (Childs 1970: 105) en die teologiese vraagstuk van die $\mathrm{Ou}$ Testament as gefinaliseerde kanon binne die geloofsgemeenskap. Omdat die Bybel duidelik kenmerke dra van die historiese omstandighede waaronder dit ontstaan het, van die historiese persone wat daaraan help vorm het en van die taal en kultuur van verskillende tydperke, kan die histories-kritiese studie van die Bybel nie nagelaat word nie. Bybelse teologie hou egter nie by daardie studie op nie. Daar was ook nog 'n dialektiese proses aanwesig waarin hierdie histories-bepaalde oorlewering in verband gebring is met die godsdiensoortuiging van die groep. Tradisie moet ook binne 'n kanonkonteks gelees en verstaan word. Die histories-kritiese benadering is nie voldoende om die Bybel as Skrif van die kerk te begryp nie. Dit is eers wanneer die Bybel binne die konteks van die kanonbegrip gelees word dat teologies gesê kan word wat dit in die verlede beteken het en wat die teologiese draagkrag daarvan in die hede is.

In 'n artikel oor die kanongehalte van die profetiese literatuur, stel Childs sy tese in meer besonderhede. Agter die huidige vorm van die 
Hebreeuse Bybel was daar 'a major and theological force' (Childs 1978: 47) werksaam wat aan die kanon sy eventuele vorm gegee het. Hierdie dryfkrag was vir die meeste van die tyd waarin die literêre vorming plaasgevind het, aanwesig. Dit was egter veral in die tyd na die ballingskap dat hierdie dryfkrag na vore getree het en sy rol gespeel het in die versameling, keuring en omvorming van die tradisie tot gesaghebbende Skrif vir die godsdiensgemeenskap. In die eindvorm van die kanon bereik hierdie dryfkrag sy hoogbloei en word ' $n$ kanon geskep wat vir alle tye staan. Childs kies daarom onomwonde vir hierdie finale vorm as die konteks waarin die teologie van die Bybel gevind sal word:

It is only in the final form of the biblical text in which the normative history has reached an end that the full effect of this revelatory history can be perceived (Childs 1978: 48).

Die finale vorm van die teks vervul nie net 'n kritiese funksie ten opsigte van alle vorige stadia van die oorlewering nie, maar verskaf ook die hermeneutiese raamwerk waarin alle vorige tradisie gelees en finaal kanoniek gevorm is. Hoewel hierdie dryfveer tot kanonvorming van die tradisie nooit los van die literêre vormingsproses gestaan het nie en met 'n mag der menigdom ander faktore saamgehang het, het dit nogtans as ' $n$ teologiese korrektief op die oorlewering ingewerk. Dit het steeds gesorg dat ' $n$ tradisie uit die verlede op so 'n wyse oorgedra is, dat dit gesaghebbend beslag kan lê op alle toekomstige geslagte van Israel' (Childs 1978: 49). Indien die Bybelse materiaal bloot historieskrities bestudeer sou word, sou hierdie vormgewing van die tradisie soos dit in die huidige kanon voorkom, nie die nodige aandag ontvang nie. Daarmee sou die teologiese denke wat in die kanonvorm gegee is, onherroeplik verlore gaan. Die kanonvorm waarin die tradisie omgewerk is, verteenwoordig juis die teologiese insigte van die geloofsgroep onder wie dit ontstaan het en wat dit as normatiewe kanon aan die nageslag wou deurgee.

In sy Inleiding tot die Ou Testament behandel Childs sy tese nog breedvoeriger. Die tradisionele historiese kritiek skiet volgens hom in drie opsigte tekort. Dit konsentreer op die ontwikkeling en vroeë stadia van die kanonvorm en nie op die eindstadium waaraan die kerklike gemeenskap gesaghebbende status verbind nie. Dit bestudeer nie die teologiese dryfvere agter die tradisieproses nie. Dit bring nie die aard van die literatuur in verband met die gemeenskap wat dit as Skrif gekoester het nie. Kanonvorming is vir Childs 'n veelfasettige proses, wat nie bloot net vanuit tradisievorming verklaar kan word nie. Die 
literêre groeiproses is nie sonder meer identiek met die kanonvormingsproses, soos Freedman beweer nie. Dit is ook nie 'n literêre groeiproses wat eers aan die einde van die proses kanonieke status ontvang nie. Dit is 'n omvattende proses wat deurgaans in Israel se geskiedenis aanwesig was, waardeur die tradisievormingsproses se gang bepaal is, maar waarin die tradisie ook telkens uitgemond het:

The authoritative Word gave the community its form and content in obedience to the divine imperative, yet conversely the reception of the authoritative tradition by its hearers gave shape to the same writings through a historical and theological process of selecting, collecting and ordering (Childs 1979: 59).

Alhoewel hierdie proses op verskillende maniere beskryf kan word, stem Childs nie met iemand soos Sanders saam dat dit 'n immer repeterende proses is wat deur die geskiedenis heen beweeg en ' $n$ literêre neerslag vorm van eksistensialistiese besinnings nie. Dit is vir Childs 'n proses wat op ' $n$ eindpunt afgestem is. Daarom is die wesenskenmerk van hierdie proses vir Childs die oorlewering van 'n Goddelike woord in ' $n$ vorm wat sodanig is dat dit gesaghebbend beslag lê op die daaropvolgende geslagte:

The heart of the canonical process lay in transmitting and ordering the authoritative tradition in a form which was compatible to function as scripture for a generation which had no participation in the original events of revelation (Childs 1979: 60).

Hierdie kanonbewustheid was voortdurend aanwesig in die kanonvormingsproses en het sy duidelikste neerslag gevind in die eindgestalte van die kanon waaroor ons vandag beskik. Die struktuur van die huidige kanonteks is daarom die belangrikste sleutel tot die ontsluiting van die teologiese betekenis van die inhoude daarvan.

Die literatuurvormingsproses en die kanonvormingsproses is nie vir Childs een identiese saak nie, maar hulle staan ook nie geheel en al los van mekaar nie. Die vorming van literatuur is ' $n$ baie meer omvattende proses as die vorming van die kanon, omdat daar veel meer faktore daarin werksaam was soos sosiaal-politieke faktore, historiese omstandighede, gebruik en verandering in literêre patrone. Al hierdie ander faktore speel egter vir Childs 'n ondergeskikte rol aan die kanoniserende teologiserende dryfveer wat op die totaal van hierdie literêre oorlewering inwerk. Omdat dit so 'n totaal komplekse historiese proses 
is wat die kanonvorming vergesel en omdat die inligting daaroor so skraps is, erken Childs wel dat die kanongeskiedenis van belang kan wees, maar vanweë die kompleksheid daarvan en vanweë die klem wat op die eindfase gelê word, ag Childs dit nie nodig om verder daaraan aandag te gee nie.

Childs se onderskeid tussen die kanonvormingsproses en die literêre tradisieproses is baie belangrik. Dit sal weer reflekteer word in die taak van die kanongeskiedenis aan die einde van hierdie artikel. Wat ongelukkig tog teleurstellend is, is dat Childs die gebruik van die kanongeskiedenis so maklik afskryf. Dit is oor hierdie saak, meer as oor enige ander onderwerp, dat die weë van Childs en ander navorsers, soos Barr en Sanders, skei. Childs verklaar wel dat die historiese dimensie nie buite rekening gelaat moet word nie. Die historiese studie na die ontwikkeling van die tradisie wat die finale fase voorafgaan, is vir Childs egter bloot daarop gerig om daardie kritiese norm wat in die finale fase aanwesig was, te identifiseer. Hierdie 'kritiese norm' waarvan Childs praat, is vir hom 'n toespitsing van die kritiese norm wat steeds aanwesig was. Dit is ' $\mathrm{n}$ ' $\mathrm{krag}$ wat voor die ballingskap ontketen is' (Childs 1979: 79), wat die steeds aanwesige kanonintensie wat tradisie normgewend aan die nageslag wou deurgee, in 'n finaliseringsrigting gedruk het. Dit is iets wat ten tyde van die finale afhandeling van die kanon die oorheersende tendens gevorm het in die kanonvormingsproses. Dit beskryf in der daad maar net die een oorheersende tendens in die finale fase van kanonvorming en gee daaraan verabsoluterende teologiese belang.

Die talle ander tendense wat ook in die finale fase aanwesig was en almal wat in vorige fase aanwesig was, word daarmee buite rekening gelaat. Sodoende ontwikkel Childs in sy teologie 'n bepaalde eendimensionaliteit waar die geheel van Bybelse materiaal op een vlak gelees word. Dit is wat Sheppard dan ook aanstip as die mankement in Childs se kanonbegrip:

Such an emphasis lends itself to the appearance of his having interest only in lines of harmony or continuity at the expense of understating the degree to which a canonical context retains historical discontinuities, conflictual inner-biblical interpretations, and persistant vaguenesses, ambiguities, or contradictory intentions (Sheppard 1985: 214).

Die kanon van die Ou Testament word nie volgens sy inherente gelaagdheid verstaan nie, maar in sy geheel op een vlak gelees as 'n 
geskrif wat in sy geheel deur die Nuwe Testament gekontekstualiseer is. Daardeur gaan die diversiteit wat so eie is an die Ou Testament geheel en al verlore - wat ook in die benadering van Wright gebeur het. Ook die diversiteit wat inherent aan die verloop van die historiese kanonvormingsproses was, wat Blenkinsopp die verskynsel van 'conflicting authority claims' (Blenkinsopp 1977: 15) noem, word buite rekening gelaat.

Childs wil wesenlik met die finale kanonisering en die Christelike kontekstualisering van daardie afgehandelde kanon in die Nuwe Testament werk. Daardeur verloor hy uit die oog dat die kanon van die Ou Testament eintlik uit drie kanonversamelings bestaan wat op verskillende tye tot afhandeling gekom het. In die proses van kanonisering was daar tye waarop die Torah reeds afgehandelde kanon was en waarin dit in die groeiende profetekanon herinterpreteer is. Sheppard het aangetoon hoe die wysheid ook op 'n stadium as konteks vir herinterpretasie vir die bestaande kanon gedien het. Redaksionele toevoegings in profetiese literatuur en boeke soos Prediker vorm hiervan die bewys (Sheppard 1980). Dit is dus noodwendig dat ' $n$ hantering van die Ou Testament as kanon ook na die voorgeskiedenis van die kanonvorming sal moet vra en die kanonvorming op verskillende historiese vlakke moet bestudeer.

\section{JAMES BARR EN DIE BYBEL AS DOKUMENT VAN GELOOFSGEMEENSKAPPE}

By Barr kom daar ' $n$ groter genuanseerdheid voor in sy behandeling van die kanonvormingsproses. Barr is van oortuiging dat die eksterne afbakening van die kamon, waardeur ander literatuur uitgesluit is van die eventuele versameling, prosesse verteenwoordig wat kenmerkend was van ' $n$ bepaalde tyd en 'n bepaalde fase in die bestaan van die volk van God. Die hele aangeleentheid 'is one full of historical contingency and relativity, full of elements which cannot be given a rational theological justification but which simply are there in their facticity' (Barr 1973: 156). Ook wat die interne aspek van die kanonisiteit aanbetref, dit wil sê die ordening en rangskikking van 'n massa, 'n diversiteit van materiaal, kan nie eensydig redeneer word nie. ' $n$ Kanon in die kanon-beginsel, soos by Wright, is nie aan te beveel nie, omdat dit eenvoudig nie reg laat geskied aan die gegewe diversiteit van die Bybel nie. Boonop verteenwoordig elke deel van die kanon op sy beurt 'n historiese gelaagdheid waarın materiaal in verskillende tydvakke in 
verskillende kontekste gefunksioneer het. Alhoewel die finale kanonkonteks die voorkeur moet geniet in die interpretasie van elke skrifgedeelte, kan die verband met die voorafgaande fases van daardie literatuur nie heeltemal buite rekening gelaat word nie:

The canonical books themselves go back to the traditions of earlier stages from which they were formed; and these traditions lie within continuities which are not represented by the sharp boundaries of the books and sections of the canon (Barr 1973: 167).

Wat Barr daarmee bedoel, het hy 'n paar jaar later breër uitgewerk in sy standpunt dat die Bybel as 'n dokument van geloofgroepe verstaan moet word. Hy werk daar met ' $n$ benadering wat Childs teenoor sy eie 'teosentriese verstaan van Goddelike openbaring', ' $n$ eksistensialistiese geskiedenis' (Childs 1979: 59) sou noem - 'n verskilpunt wat duidelik na vore kom in die huidige kanondiskussies. Barr sien die verskillende geloofsgroepe wat oor die eeue heen bestaan het, as die voedingsbodem van die Skrif wat uiteindelik tot stand sou kom. Binne die bestaan van hierdie geloofsgemeenskappe is die tradisie op ' $n$ baie vloeibare wyse hanteer. Die tradisie is egter nie op 'n lukraak wyse hanteer nie, maar op so ' $n$ wyse verwerk en geaktualiseer dat dit telkens aan 'n volgende geslag as 'n lewende en aktuele regula fidei deurgegee kon word. Op ' $n$ bepaalde stadium het hierdie oorlewering skriftelike vorm aangeneem, maar daarmee nie opgehou om te funksioneer as geloofsparadigma vir toekomstige geloofsgemeenskappe nie. Daarmee het Barr aangedui dat 'n geskrewe en gefinaliseerde kanon maar slegs een fase van kanongeskiedenis verteenwoordig en dat die kanon nie soseer vanuit sy geskrewenheid of gefikseerdheid as kanon gefunksioneer het nie, maar vanuit sy paradigmatiese funksionaliteit. $\mathrm{Al}$ het Barr nie sy standpunt met konkrete kanongeskiedenis gestaaf nie, is daarmee egter nogmaals bevestig dat die bepaling van die rol wat die Bybel as kanon speel, nie net vanuit 'n gefinaliseerde fase verstaan moet word nie, maar vanuit die totale geskiedenis van die kanon voor en na finalisering.

\section{JA SANDERS EN KANONKRITIEK}

Sanders dink in dieselfde rigting as Barr, maar gee baie meer aandag aan die geskiedenis van die kanonvorming en aan al die faktore wat daarin ' $n$ rol speel. In sy kommentaar op Barr se The Bible in the modern world, steun Sanders Barr heelhartig dat kanonisering 'n historiese 
proses is. Kanonisering behels nie in eerste instansie die beslissings van konsilies oor die omvang van die kanon nie, maar is ' $n$ veelsydige historiese proses wat binne die historiese konteks waarin dit plaasgevind het, bestudeer moet word. Veral die tydperke van die sesde eeu voor Christus en die eerste eeu na Christus moet in besonderhede bestudeer word. Dit is juis wat by Barr kortkom dat hy wel tereg aantoon dat die kanon vanuit ' $n$ funksionele hoek verstaan moet word, maar dat hy dit nie onderbou met 'n studie van die geskiedenis van kanonvorming nie. Die studie van tradisiekritiek, vergelykende Midrasj-navorsing en kanonkritiek bied juis die demonstrasie uit die kanongeskiedenis dat kanonisering die funksie was wat aan die tradisie in die verskillende geloofsgemeenskappe verleen is. Deur na te gaan hoe geloofsgemeenskappe tradisie oorgeneem, geïnterpreteer en geformuleerd deurgegee het aan die volgende geslagte, kan verstaan word wat kanonisering behels. Deur juis te sien hoe kanonisering telkens tussen die twee pole werk van oorgelewerde teks en kontekstualiserende en aktualiserende geloofsgemeenskap, kan deur 'dinamiese analogie' (Sanders 1974: 329) 'n model gevind word vir die wyse waarop die kanon vandag in die geloofsgemeenskap kan funksioneer. In daardie sin sou Barr dan ook geregverdig wees om van die Bybelse kanon as 'n paradigma te praat: "The Bible should be looked upon as a paradigm on how one may conjugate the verbs of God's past and present activity and presence' (Sanders 1974: 329). Sanders bring dus ook soos Wright die vraagstuk van die kanonisiteit van die Ou Testament in verband met sy huidige teologiese funksionering via die kanonvormingsproses. By Sanders word die verbinding egter gesubstansieer deur uitvoerige navorsing van die verloop van die kanonvorming.

Sanders beskryf sy benadering as kanonkritiek (canonical criticism). Dit is navorsing wat tweeledig funksioneer.

(It) provides both a set of tools for reading the Bible through understanding the canonical process in antiquity and a means of revitalizing and reviving the very concept of canon as the book of the churches and synagogues (Sanders 1984a: 18).

Daar is twee aspekte aan hierdie navorsing verbonde: die kanonproses en kanonhermeneutiek. Die kanonproses word as ' $n$ historiese proses gesien wat in vier fases verloop het: fase van die Oerteks, van die aanvaarde teks, van die oorgelewerde teks en dié van die Massoretiese teks. Verskillende bestaande dissiplines asook 'n paar nuwer dissiplines wat uit die kanonkritiek self ontwikkel het, word in hierdie 
navorsing betrek. Die literêr-historiese dissiplines, wat oor die afgelope 200 jaar ontstaan het en geraffineer is, word hoofsaaklik vir die navorsing na die Oerteks gebruik. Op hierdie terrein word gesoek na die mees oorspronklike uitsprake, die sogenaamde ipsissima verba van die Bybelouteurs. Die nuwer navorsing na die Nachleben van oorgelewerde tradisie word ingespan vir die tweede fase van die aanvaarde teks. Dit is die belangrike tydperk tussen die sesde eeu voor Christus tot die eerste eeu na Christus, toe daar ' $n$ beweging was vanaf ' $n$ groot variasie kanonversamelings na die algemene aanvaarding van een weergawe van die kanonversameling. Die derde tydvak strek vanaf die eerste eeu na Christus toe daar een enkele oorgelewerde teks van die kanon was en mond uit in die tydvak van die Massorete en hulle hantering van die kanonteks.

Terwyl elke fase sy eie karakteristieke historiese, literêre en sosiale kenmerke het, is daar tog 'n bepaalde kontinuiteit aanwesig. Sanders verwys daarna as die 'ontology of scripture' (Sanders 1979: 25). In hierdie ontologie het daar voortdurned 'n verskuiwing plaasgevind. Dit het te doen met die geaardheid van ' $n$ kanon wat altyd 'n vaste sowel as 'n aanpasbare element het ('stable and adaptable' - Sanders 1984b: 404). Binne die konteks van die geskiedenis is daar 'n kanon hermeneutiek aanwesig waarvolgens die kanon gevorm word rondom 'n vaste kern wat voortdurend aangepas word. Hierdie kanon-hermeneutiek kan van verskillende tegnieke gebruik maak. Dit is juis die taak van die tweede been van die kanonkritiek, naamlik die kanon-hermeneutiek. om vas te stel: 'The means whereby Israel, Judaism, and the church spanned the gaps between inherited faith and new cultural settings' (Sanders 1984b: 403). Deur hierdie beginsels en reëls te beskryf, kan die voorskrifte dan aan die huidige geloofsgemeenskap voorsien word hoe die Bybel as kanon hanteer kan word.

In Sanders se kanonkritiek word daar in twee rigtings beweeg met die dissiplines van die Ou-Testamentiese wetenskap. Aan die een kant word bykans al wat ' $n$ dissipline is, betrek by 'n groter teologiese sintese. Om die totale konteks van elke fase van kanonvorming te bestudeer, is daar insette van die navorsing na die geskiedenis, literatuur, sosiologie, kennispsigologie en godsdiensfenomenologie nodig. Al hierdie insette word betrek in 'n poging om te verklaar hoe daar gelees en verstaan is aan die vormende kanontradisie. Aan die ander kant lei kanonkritiek dikwels tot die ontstaan van nuwe dissiplines en die herdefinisie van bestaande dissiplines. In die geval van die tekskritiek het Sanders aangetoon dat dit 'n 'baie meer beperkte dissipline' 
(Sanders 1979: 8) is as wat tot hiertoe aanvaar is. Die groei van die teks in die verskillende fases van kanonvorming verhoed dat tekskritiek op die tradisionele manier gebruik kan word. Die tweede fase word gekenmerk deur 'n verskuiwing vanaf 'n baie vloeibare toestand na ' $n$ gestabiliseerde toestand. Daar vind 'n beweging plaas vanaf ' $n$ veelheid van vloeibare tekste wat in omloop was na 'n geleidelike uitkristallisering na een ongeveer algemeen aanvaarde teks. Vir die tekskritiek hou dit in dat tekste uit die tweede tydvak van teksvorming nie langer met die ou gedagte dat daar slegs een oorspronklike teks is, hanteer kan word nie. Die vroegste Qumrantekste moet dus aan die kant van vloeibare tekste geplaas word en tekste soos die wat by $\mathrm{Mu}$ rabba'at, Hever en Massada gevind is, aan die ander kant van tekste waarin die 'ontologie van Skrif' al aansienlike verandering ondergaan het. Dit is eers tekste uit die derde fase wat met die ouer tekskritiese werkswyses hanteer kan word.

Kanonkritiek het ook die behoefte geskep aan die ontstaan van nuwe selfstandige dissiplines. Een van hulle was die ontstaan van 'n dissipline wat aandag gee aan antieke Bybelinterpretasie, bekend as vergelykende Midrasj-studie. Hierdie dissipline gee aandag aan die verskynsel van Skrifinterpretasie in die vroeë Judaïsme en die eventuele invloed daarvan op die latere Christendom. Hierdie tydperk was gekenmerk deur diepliggende historiese en konseptuele veranderinge wat vanaf die Bybelse tydperk na die begin van die Rabbynse Judaïsme ingetree het. Midrasj word dan die omvattende bedryf waardeur Skrif 'was wrapped in the garment of contemporary perceptions, issues, and concerns, and thus transformed; in turn, the contemporary world was perceived in the light of scripture, and thereby illuminated' (Miller 1984: 595).

Dit sluit aan by die navorsing van die kanonhermeneutiek. Hier word prosesse aangetoon wat aan die werk was terwyl die proses van kanonvorming nog nie afgehandel was nie. Daarom kon dit dus neerslag vind in die uiteindelike opset van die kanon. Dit is gevolglik 'n saak waaroor navorsing van direkte belang is vir die kanonkritiek:

Thus, the process of attributing unique and permanent authority to earlier tradition, i.e., the process of canon, and the emergence of midrashic procedures belong in their initial phases to study of the formation and shape of the Hebrew Scriptures (Miller 1984: 596).

Die ontdekking van die Qumranrolle, die toenemende bewuswording 
van die diversiteit van geloofsgemeenskappe in die tweede tydvak van kanonwording en die bevinding van die verskeidenheid van metodes wat onder Midrasj resorteer, het tot die aspek van die vergelykende Midrasj-studie gelei.

Bestaande dissiplines, soos die navorsing na die profeteliteratuur, word deur kanonkritiek in 'n bepaalde rigting gestimuleer. Die ontstaan van 'n ryk verskeidenheid interpretasiemodelle as gevolg van die verskeidenheid van geloofsgemeenskappe wat deur die diaspora veroorsaak is, het ook neerslag gevind in die pluriforme aard van die kanon wat tot stand gekom het. Die groot diversiteit en selfs onderlinge teenstrydigheid van materiaal in die huidige kanon, kan verklaar en hanteer word vanuit die Kanonkritiek. Sanders meen dat die tyd tussen die vernietiging van die eerste tempel (sesde eeu voor Christus) en die vernietiging van die tweede tempel (eerste eeu na Christus) gekenmerk is deur twee teenoorstaande en naasmekaarwerkende opvattings oor die Woord van God. Enersyds was daar die gedagte dat die lewende woord van God altyd dinamies nuut en vars is en andersyds die gedagte dat tradisie telkens stabiliseer en gevolglik voortdurend aangepas moet word vir elke nuwe historiese konteks (Sanders 1979: 20-23). Blenkinsopp sien die twee spanningspole waartussen die diversiteit van tradisie en interpretasie van tradisie ontstaan as die van normatiewe orde en profesie. Die finale Toravorming is die uiting van die pool van normatiewe orde. Die opkoms van 'n profetekanon verteenwoordig ' $n$ herstel van balans tussen die normatiewe orde en profesie. Kanonvorming is ' $n$ proses van 'conflicting authority claims... about the right to provide a normative version of the tradition' (Blenkinsopp 1977: 15). Die diversiteit in die kanon vandag is grootliks die gevolg van hierdie slingerbeweging tussen twee spanningspole waarin daar meegeding is om die oorgelewerde tradisie aan die latere geslag deur te gee. Veral in die nuwer navorsing na die verskille tussen valse en ware profesie by Israel word op hierdie sake ingegaan. Die argumente tussen Jesaja of Jeremia en hulle opponente het gewoonlik of oor die profeteroeping òf oor die verstaan van die tradisie gehandel. Profetiese uitsprake wat wedersyds weersprekend is, verteenwoordig dikwels totaal verskillende hermeneutiese raamwerke. Profesie is nie noodwendig ò vals ò waar nie, maar hang van die bepaalde omstandighede af waaronder dit gesê is. In' Esegiël 33: 24 word berig dat Esegiël 'n tipologiese verstaan van Abraham se ontvangs van die beloofde land teenstaan. In Jesaja 51: 2-3 gebruik Deutero-Jesaja presies dieselfde tipologiese afleiding wat Esegiël afgewys het. Die verskil in historiese 
konteks tussen die twee profete gee dus aanleiding tot twee verskillende uitsprake, wat tog wel albei as deel van die kanon aanvaar is. Die kanonvormingsproses en die gevolglike kanonvorm self, toon daarom 'n geweldige ryk skakering van gesigshoeke wat egter alles binne die een proses geakkommodeer is. Dit werp alles meer lig op die kanonvormingsproses en sy omstandighede.

Terwyl die kanonproses volgens verskillende historiese tydperke en 'n groot verskeidenheid eksterne faktore bestudeer moet word, was daar wel bepaalde tendense aanwesig wat van meer direkte teologiese belang is. Hierna word verwys in die bogenoemde kanonhermeneutiek. In die geloofsgemeenskap bestaan daar tradisionele waardes wat oorgeneem word en gekontinueer word in ' $n$ ander konteks as die waarin die waardes vroeër gefunksioneer het. Deur 'relecture' (Frans) kan hierdie waardes gehandhaaf word of in die nuwe situasie aktualiteit behou deurdat dit daarby aangepas word. Dit is die taak van die Kanonkritiek om vas te stel 'what the function of a tradition, in whatever form it is found, had when called on for his or her community by a tradent' (Sanders 1984a: 24). Die omstandighede, persone en gemeenskap wat meegewerk het in die aanvaarding en deurgee van 'n kanondeel, word so nagegaan. Tussen die drie interaktiewe pole van kanonhermeneutiek; die teks of tradisie en die situasie waaronder die tradisie hanteer is en die kanonvorming dus plaasgevind het, behoort daar na vore te kom 'a permissible hermeneutic range that indicates what is hermeneutically fair, according to the canonical process, to use in the believing communities today in representing and resignifying a biblical tradition or text to address new problems' (Sanders 1984a: 61-62).

\section{KANONKRITIEK EN KANONGESKIEDENIS}

Childs wou nie van kanongeskiedenis gebruik maak in sy Ou-Testamentiese teologie nie. Hy deins terug voor die ingewikkeldheid van die saak. Barr se tekortkoming is juis dat hy bepaalde kanonfunksies vir die hede aantoon sonder om dit te substansieer met gegewens uit die kanonvormingsproses. Sanders pak die taak aan om op die geskiedenis van die kanonvorming in te gaan. Sanders maak egter nêrens van 'n volledige uitgewerkte kanongeskiedenis gebruik nie. Dit is onvermydelik dat so 'n omvattende kanongeskiedenis een of ander tyd geskryf sal moet word. So " $n$ geskiedenis sal die hele tydperk vanaf die middel van die tweede millennium voor Christus tot in die eerste eeu na Christus moet bestudeer. Alle tersaaklike inligting - polities-histories, sosio-religieus, psigo-kultureel, opsommenderwys alle inligting 
wat enigsins kan lig werp op die omstandighede van die bestaan van die tradente - moet versamel word en in 'n geheelbeeld verwerk word vir elke fase van die geskiedenis. Binne hierdie raamwerk moet 'n tweede binnesone van bestudering gestel word. Hierin moet tradisievorming, literatuurvorming, interpretasie vabn oorlewering, alles wat lig kan werp op die proses waarvolgens gemeenskappe van mense kommunikeer, literatuur tot stand bring, literatuur vervang, behou, verwerp of aanvul, bestudeer. In ' $n$ derde binnekring van studie moet 'n ondersoek staan na die motiverings van die verantwoordelike gemeenskappe onder hierdie bepaalde sosio-historiese omstandighede en literêre dryfkragte om die reeds gevormde kanongedeeltes op 'n bepaalde wyse teologies te hanteer en op 'n bepaalde wyse aan die toekomende geslag deur te gee. Die drie sones moet as interaktiewe gebiede bestudeer word, wat tegelyk ook in verband staan met die verlede van die kanonproses asook sy toekomstige verloop. Uit die boustene van so 'n geskiedenis kan 'n Ou-Testamentiese teologie die nodige samehange aantoon in die Ou-Testamentiese literatuur, die teologiese riglyne aantoon en ' $n$ toepaslike teologie skryf.

\section{Literatuurverwysings}

BARR, J 1973. The Bible in the modern world. London: SCM.

BLENKINSOPP, J 1977. Prophecy and canon: A contribution to the study of Jewish origins. Notre Dame: University of Notre Dame Press.

CHILDS, BS 1970. Biblical theology in crisis. Philadelphia: Westminister.

CHILDS, BS 1978. The canonical shape of the prophetic literature. Interpretation 32, $46-55$.

CHILDS, BS 1979. Introduction to the Old Testament as Scripture. London: SCM.

CLEMENTS, RE 1978. Old Testament theology: A fresh approach. London: Marshall, Morgan \& Scott.

HASEL, GF 1985. Major recent issues in Old Testament theology 1978-1983. JSOT 31, $31-53$.

MILLER, MP 1984. Midrash IDB, Supplementary Volume, 593-597.

OBERHOLZER, JP (1976). Die soeke na 'n Bybelse teologie. HTS 32/3\&4, 151-160.

SANDERS, JA 1974. Reopening old questions about Scripture. Interpretation 28, 321-330.

SANDERS, JA 1979. Text and canon: Concepts and method. JBL 98/1,5-29.

SANDERS, JA 1984a. Canon and community: A guide to canonical criticism, Philadelphia: Fortress.

SANDERS, JA 1984b. SV Hermeneutics. IDB, Supplementary Volume, 402-407.

SHEPPARD, GT 1980. Wisdom as a hermeneutical construct: $A$ study in the sapientalizing of the Old Testament. Berlyn: De Gruyter.

SHEPPARD, GT 1985. The anti-Assyrian redaction and the canonical context of Isiah 1-39. JBL 104/2, 193-216.

TERRIEN, S 1984. Biblical theology: The Old Testament (1970-1984. Biblical Theology Bulletin 15, 127-135.

TIDWELL, NL (1975). Pentateuchal criticism and canonical criticism, in Van Wyk, WC (Ed), Studies in the Pentateuch, 45-56. Pretoria: NHW-Pers.

WRIGHT, GE 1969. The Old Testament and theology New York: Macmillan. 